\title{
Pre-treatment and Suitable Reagent Enabled a Reliable and Consistent for Molecular Detection of Fusarium oxysporum f.sp. cubense Tropical Race 4 (Foc TR4)
}

\author{
Listya Utami Karmawan ${ }^{1,2}$, Fenny Martha Dwivany ${ }^{1,3,4}$, Rizkita Rachmi Esyanti' ${ }^{1}$ I Nyoman Pugeg Aryantha ${ }^{1,3^{*}}$ \\ 'School of Life Sciences and Technology, Institut Teknologi Bandung, Bandung, Indonesia \\ ${ }^{2}$ Faculty of Biotechnology, Atma Jaya Catholic University of Indonesia, Jakarta, Indonesia, \\ ${ }^{3}$ Biosciences and Biotechnology Research Centre, Institut Teknologi Bandung, Bandung, Indonesia \\ ${ }^{4}$ Bali International Research Center for Banana, Universitas Udayana Bukit Jimbaran, Badung, Indonesia
}

\section{ARTICLE INFO}

Article history:

Received September 1, 2018

Received in revised form December 24, 2018

Accepted April 9, 2019

\section{KEYWORDS:}

DNA isolation,

genome pre-treatment,

Foc detection method,

banana,

Fusarium wilt,

food and agriculture

\begin{abstract}
Fusarium wilt which is caused by the soil-borne fungus, Fusarium oxysporum f.sp. cubense (Foc), is one of important diseases in banana plant. Foc tropical race 4 (Foc TR4) is the most pathogenic race which could infect various banana cultivars including Cavendish cultivar which was previously considered as resistant cultivar. Molecular detection of Foc using PCR analysis is indispensable to determine the race of Foc. We demonstrate a faster DNA isolation procedure described in previous method by substituting sodium acetate precipitation with ammonium acetate precipitation without affecting the result. Based on our experience, some fungal genomes were troublesome to be amplified. We suggested pre-treatment step prior to amplification procedure by incubating fungal DNA in $65^{\circ} \mathrm{C}$ for 10 minutes for any samples of fungal genome, including stubborn samples, before mixing into PCR mix reagent. PCR reagents should be tested for stubborn samples since some of the reagents were unable to amplify the desired DNA fragment. Pre-treatment and the choice of robust PCR reagent should be taken into consideration for a reliable and consistent Foc TR4 molecular detection result.
\end{abstract}

\section{Introduction}

Indonesia was the third largest banana producing country after India and China with total banana production up to 7,007,125 tonnes in 2016 according to FAOSTAT database (FAOSTAT 2018). In Indonesia, particularly in rural area, bananas are commonly cultivated in backyard plantations for local consumption. Larger commercial or government banana plantations are supplying either domestic or international market demand. Plant diseases are biotic constraints which affect banana production significantly. Plant diseases are mostly caused by a microorganism such as fungi, bacteria, or viruses. For instance, fungal-induced disease (e.g. Fusarium wilt, Sigatoka leaf spots), bacterial wilt diseases (e.g. Moko disease, blood disease, Xanthomonas wilt), and virus-induced diseases (e.g. bunchy top and banana streak) are important banana plant diseases (Ploetz

\footnotetext{
* Corresponding Author

E-mail Address: nyoman@sith.itb.ac.id

and Evans 2015). Fusarium wilt, especially which is caused by Fusarium oxysporum f.sp. cubense Tropical Race 4 (Foc TR4), is being the most devastating disease.

F. oxysporum strains is divided into forma speciales based on their host specificity and pathogenicity. Earlier, forma speciales of fungal culture have been characterized by vegetative-compatibility grouping (VCG) method (Katan 1999). Recently, numerous molecular detection method and sets of specific molecular marker are being developed to detect the existence of genus Fusarium in samples or fields. For instance, Loop-mediated isothermal amplification (LAMP) which is simple, fast, sensitive, and specific, and can be used directly in the field was used to detect Foc race 4 in infected banana plant tissue in resource-poor settings (Li et al. 2012). ITS and RAPD marker usage have been developed for identification and characterization of Fusarium species in tomato (Singha et al. 2016). A specific molecular marker for Fusarium oxysporum species was developed from 5' portion of translation elongation factor $1 \alpha$ (TEF-1 $\alpha)$ 
coding region (O’Donnell et al. 1998). In addition, a molecular marker specific for Foc TR4 located on the intergenic spacer (IGS) region of the ribosomal operon was developed (Lin et al. 2009). Dita et al. 2010 improved primer pair described by Lin et al. 2009 by designing a new pair of primers based on two single nucleotide polymorphisms (SNPs) located in the same region. This primer was able to detect uniquely the Foc TR4 VCG 01213, which encompass the tropical race 4. Most of these molecular detections require a fast, consistent, and reliable practice of fungal genome isolation and PCR procedure. In this study we describe the improvement of fungal DNA isolation method and developed a pre-treatment procedure which was advantageous for stubborn fungal genome samples which were troublesome for PCR amplification. We demonstrate that pretreatment step showed more consistent and reliable result for Foc TR4 molecular detection using universal ITS fungal primer sets (ITS5/4, White et al. 1990), specific marker for Fusarium species (EF-1/2, O’Donnell et al. 1998), and specific marker for Foc tropical race 4 (FocTR4-F/R, Dita et al. 2010).

\section{Materials and Methods}

\subsection{Fungal Samples Preparation and Storage}

Foc TR4 (VCG 01213) was obtained from the Indonesian Tropical Fruit Research Institute (Solok, Indonesia). Foc TR4 culture was grown on Potato Dextrose Agar (PDA) at room temperature and stored as glycerol stocks in $-20^{\circ} \mathrm{C}$. Fungi that live inside a healthy and a Fusarium wilt-infected banana plant was collected by extracting a small piece of pseudostem tissue. Samples were taken from banana plants grown in villagers' backyard plantations in Buleleng, Bali ( $8^{\circ} 10^{\prime} 43^{\prime \prime}$, $114^{\circ} 59^{\prime} 25^{\prime \prime}$, at \pm 3 m above mean sea level). Plant tissue samples were placed inside separate plastic bags in a cool box during transportation. Samples were stored in a refrigerator at $2-8^{\circ} \mathrm{C}$ until the time of analysis. Small pieces of tissue from healthy and infected banana were cut and placed on PDA medium to allow the growth of any traces of fungi living inside the plant tissue. Samples were grown in the room temperature.

\subsection{Fungal Macroscopic and Microscopic Morphology}

Fungal culture grown on PDA plates were examined for growth characteristic and pigment formation and morphological properties. According to visual examination, the shape, size, colony elevation, and the color of fungal culture were documented and recorded. Microscopic structure such as mycelium and spores were examined using a light microscope. Fungal mycelia were scraped from the PDA plates using a sharp needle and placed into a drop of $0.85 \% \mathrm{NaCl}$ on a microscope slide. Mycelia were carefully separated using the tip of needle and stained with a drop of lactophenol cotton blue. Stained fungal samples were covered with an object glass before light microscopy examination or loaded into Neubauer haemocytometer chamber for light microscope observation with 200-400x magnification. Fungal spore and other microscopic structure size were determined based on the scales inside Neubauer haemocytometer chamber.

\subsection{Fungal DNA Isolation}

Fungal genomes were isolated from the 3-7 days old mycelia of Foc TR4 pure culture and mixed fungal culture grew from Fusarium wilt-infected and healthy banana plant tissue. Fungal genomes were also isolated directly from Fusarium wilt-infected or healthy banana plant tissue. Genomic DNA was extracted from filamentous fungi and plant tissues according to the method described by Möller et al. (1992) with slight modification as follow. Mycelia was scraped from the medium using a scalpel. Mycelia or plant tissues were ground with liquid nitrogen. About 30-60 mg powdered samples were transferred to $500 \mu \mathrm{l}$ TES buffer supplemented with $100 \mu \mathrm{g}$ PVP and then incubated for 30 minutes in $65^{\circ} \mathrm{C}$. Subsequent steps incorporating the addition of $\mathrm{NaCl}$ and CTAB, C:I, and DNA precipitation procedure using sodium acetate and isopropanol were done according to Möller et al. (1992), further referred to as Method A. As an alternative, we substituted DNA precipitation method described in Möller et al. (1992) with ammonium acetate DNA precipitation as described in Sambrook and Russell (2001), further referred to as Method B. Using ammonium acetate DNA precipitation of Method B, 30 minutes incubation step at $0^{\circ} \mathrm{C}$ after the addition of $\mathrm{C}: \mathrm{I}$ (24:1) was omitted. Subsequently, the addition of ammonium acetate (2.0-2.5M in final concentration), isopropanol (0.6-0.7 volumes), and $70 \%$ ethanol for washing DNA pellets were performed according to Method B. Fungal genome DNA isolates were dissolved in $30 \mu \mathrm{l}$ TE buffer. Isolated fungal genomes were visualized using gel electrophoresis by loading $3 \mu \mathrm{l}$ of samples on $1 \%$ agarose gel. Concentration and 
purity of DNA genomes were determined by UV-vis spectrophotometer.

\subsection{Molecular Detection of FocTR4}

Despite fungal genomes isolated from samples used in this experiment, another five samples which were previously isolated from Fusarium wiltinfected banana from various place in Bali island were used in this experiment to extend the number and type of samples used. These samples were isolated from various cultivars of banana, comprising a Pisang ambon cultivar (Pa1), Pisang ambon marge (Pam1), Bading kayu susu (BKS3), Bading kayu ketip (BKK3), and Raja sereh (Rs2) cultivar, respectively. Fungal genomes samples were diluted 10 times or adjusted to $5 \mathrm{ng} / \mu \mathrm{l}$. Fungal genomes were pretreated by heating at $65^{\circ} \mathrm{C}$ for 10 minutes before mixed into PCR reagent. Samples were quickly placed on ice after incubation. Samples without heating were used as control. Three different PCR mix reagents from different manufacturers were compared, reagent A (Kapa2G Fast ReadyMix PCR Kit, Cat. number KK5101), B (GoTaq ${ }^{\circledR}$ Green Master Mix, Cat number M7121) and C (MyTaq ${ }^{\mathrm{TM}}$ Red Mix 2× Bioline, Cat. number BIO-25043), respectively. PCR mix with total reaction volume $10 \mu \mathrm{l}$ was prepared as follow: $5 \mu \mathrm{l}$ PCR mix, $0.5 \mu \mathrm{l}$ forward and reverse primers ( 10 $\mathrm{pmol} / \mu \mathrm{l}), 2 \mu \mathrm{l}$ of diluted fungal genomic DNA, and $2 \mu \mathrm{l}$ nuclease-free water. PCR reactions were performed with the Veriti ${ }^{\mathrm{TM}}$ 96-Well Thermal Cycler with initial denaturation $\left(95^{\circ} \mathrm{C}, 5\right.$ minutes); followed by 30 cycles of denaturation $\left(95^{\circ} \mathrm{C}, 30\right.$ seconds), annealing (30 seconds at different temperatures shown in Table 1 and extension $\left(72^{\circ} \mathrm{C}, 1\right.$ minutes); and post extension $\left(72^{\circ} \mathrm{C}, 7\right.$ minutes $)$. PCR products $(3 \mu \mathrm{l})$ were loaded on $2 \%$ agarose gel for visualization. Gels were stained with ethidium bromide and visualized on UV transilluminator.

ITS, TEF- $1 \alpha$, and Foc TR4 DNA fragments from Foc TR4 pure culture, Foc TR4 DNA fragments from crude fungal genome isolated from Fusarium wiltinfected tissue, and ITS, TEF- $1 \alpha$, and FocTR4 DNA fragments isolated from purple colony recovered from healthy tissue were sent to Macrogen, Inc.
Korea for purification and direct sequencing using appropriate primer pairs. Sequences were aligned and edited using Seqtrace 0.9.0 (Stucky 2012) and final sequences were submitted to GenBank. BLAST tool (Altschul 1997) was used to compare final DNA sequences to GenBank database for similarity prediction.

\section{Results}

\subsection{Fungal Macroscopy and Microscopy Morphology}

Foc TR4 pure culture showed a rapid growth to $1.5-2 \mathrm{~cm}$ growth in diameter within 3 days after subcultured on PDA at room temperature. Colony showed the abundance of aerial hyphae with a flat and woolly to cottony mycelia (Figure 1a and b). Mycelia was white in its early growth, subsequently purple pigments were spreading starting from the center of inoculum (Figure 1a). Branched with septate hyaline hyphae, macroconidia, microconidia, and chlamydospores were observed (Figure 1c-f). After 3-7 days, two types of conidia were observed, macroconidia and microconidia, respectively. Macroconidia were larger $( \pm 20 \mu \mathrm{m})$ with a slightly curved and fusiform shape (Figure 1d), some macroconidia grew from intercalary phialides. Microconidia were smaller $( \pm 10 \mu \mathrm{m})$ with ellipsoidal shape (Figure 1e). Abundant formation of spherical shape chlamydospores $( \pm 5 \mu \mathrm{m})$ was observed in older culture of Foc TR4 (Figure 1f).

The fungal culture grown from healthy banana tissue (Figure 2) showed a fungi colony which were macroscopically suspected as Fusarium genus. This suspected colony was fast growing with aerial white and purple mycelium (Figure $2 \mathrm{~b}$ ). Subsequently, this culture was putatively identified as $F$. proliferatum based on molecular identification using ITS sequencing. Branched hyphae and conidia of $F$. proliferatum species were observed microscopically (Figure 2c). White, orange, and purple culture were observed from mixed culture grew from Fusarium wilt-infected (Figure 2e and f).

Table 1. Primer pairs used for Foc TR4 molecular detection

\begin{tabular}{|c|c|c|c|c|}
\hline Primer & DNA sequences $\left(5^{\prime} \rightarrow 3^{\prime}\right)$ & Amplicon size (bp) & Annealing temperature $\left({ }^{\circ} \mathrm{C}\right)$ & References \\
\hline FocTR4-F & CAC GTT TAA GGT GCC ATG AGA & 463 & 60 & (Dita et al. 2010) \\
\hline FocTR4-R & CGC ACG CCA GGA CTG CCT CGT GA & & & \\
\hline EF-1 & ATG GGT AAG GAR GAC AAG AC & 648 & 57 & (O’Donnell et al. 1998) \\
\hline EF-2 & GGA RGT ACC AGT SAT CAT & & & \\
\hline ITS5 & GGA AGT AAA AGT CGT AAC AAG G & 550 & 55 & (White et al. 1990) \\
\hline ITS4 & TCC TCC GCT TAT TGA TAT GC & & & \\
\hline
\end{tabular}



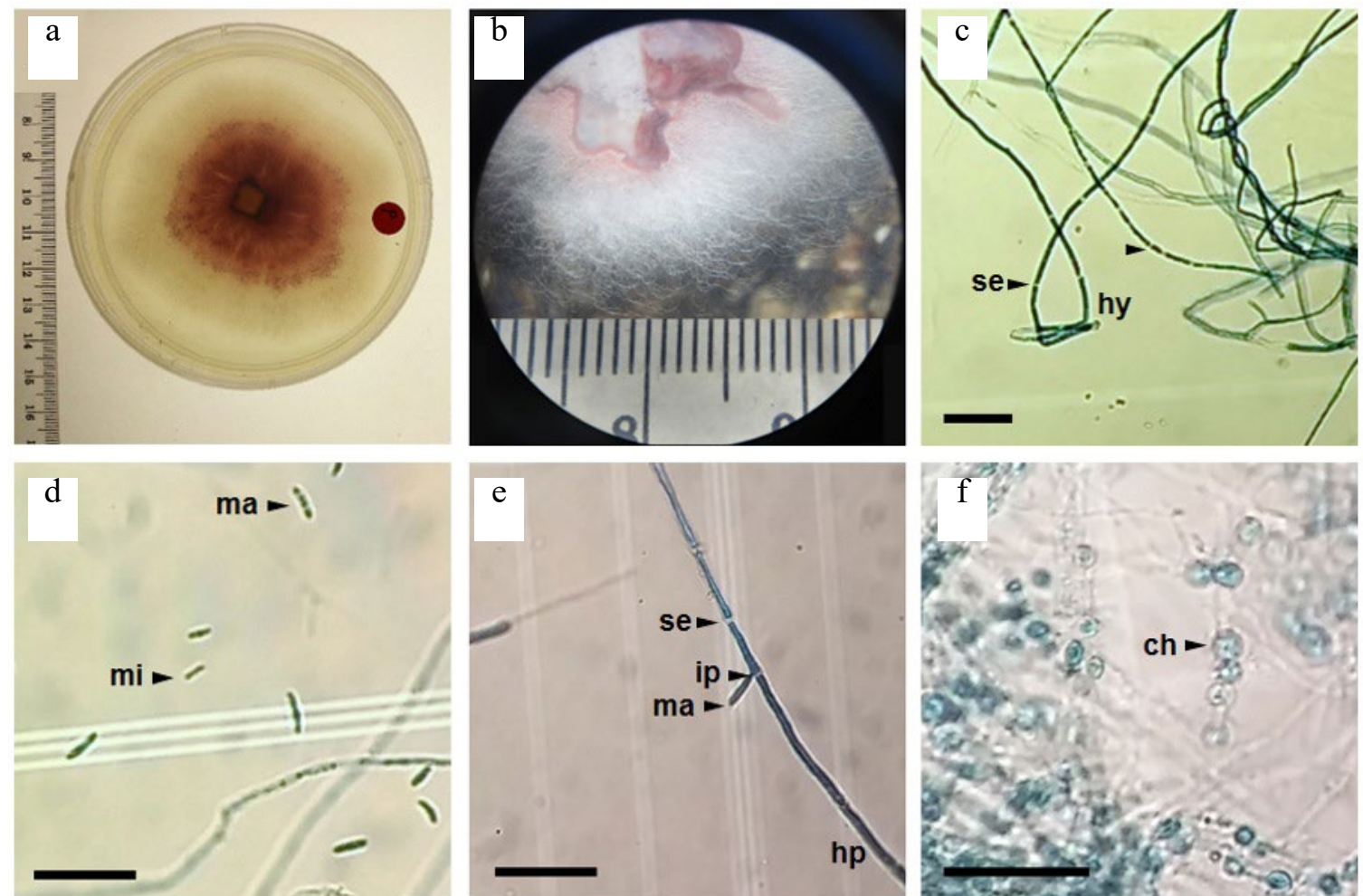

Figure 1. Observation of Foc TR4 grown in PDA at room temperature. (a) A white purple culture of Foc TR4 at 11 days after subculturing. (b) Flat, woolly to cottony aerial hyphae of Foc TR4. (c) A septate (se) hyaline hyphae (hy). (d) Macroconidia (ma) and microconidia (mi). (e) A macroconidium produced from intercalary phialide (ip) on a hypae. (f) Chlamydospores (ch) on hyphae of Foc TR4 late culture. Bars represented $50 \mu \mathrm{m}$
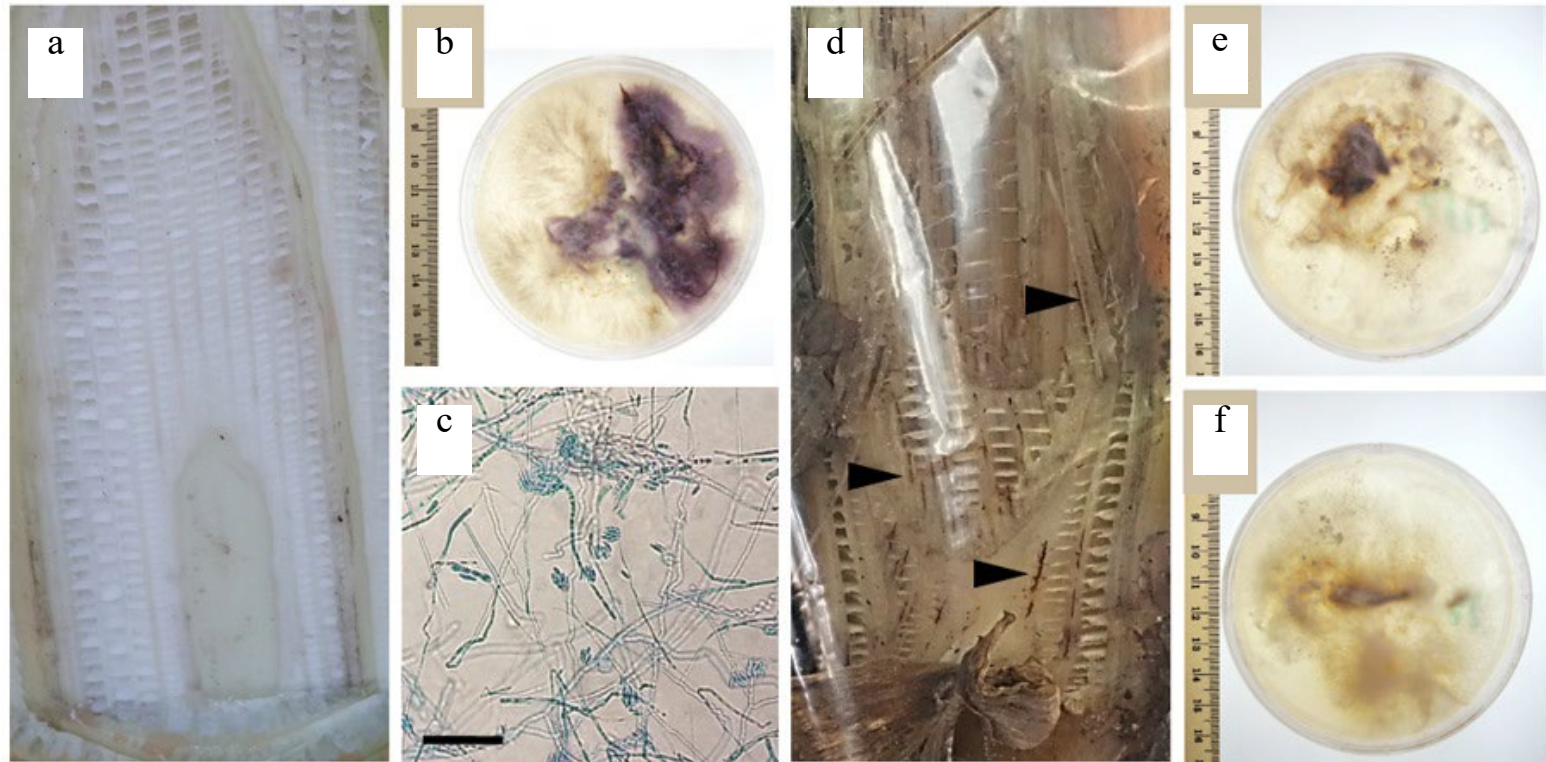

Figure 2. (a) Tangential slice of a healthy banana pseudostem. (b) Mixed culture from pseudostem of healthy banana plant. Purple colony was subsequently regarded as F. proliferatum. (c) Microscopy of F. proliferatum. Scale bars, $50 \mu \mathrm{m}$. (d) Pseudostem of Fusarium wilt-infected banana plant sliced tangentially; arrows showed vascular discoloration symptom. (e, f) Mixed culture from Fusarium wilt-infected banana pseudostem tissue 


\subsection{Comparison of Optimized Fungal Genome Isolation}

Combination of fungal isolation method described in Method A starting from cell disruption to $C$ :I extraction combined with ammonium acetate DNA precipitation as described in Method B greatly reduced DNA isolation time if compared to Method A alone. The combination of these methods resulted in a sharp and intact genome DNA observed on agarose gel with no significant difference in DNA genome quality if compared to Method A itself (Figure 3).

\subsection{Fungal Molecular Identification}

Foc TR4 pure culture sample was unable to be amplified without pre-treatment step prior to amplification procedure by incubating fungal DNA in $65^{\circ} \mathrm{C}$ for 10 minutes. ITS fragment was successfully amplified using PCR mix reagent $C$, combined with pre-treatment of $65^{\circ} \mathrm{C}, 10$ minutes of genome samples before mixing (Figure 4a). A further trial using different samples of fungal genomes with PCR mix reagent $B$ without pre-treatment for amplification of ITS DNA fragment showed that some fungal ITS DNA fragments were not successfully amplified (Figure 4b).

There were some discrepancies between the result of PCR reaction using reagent $B$ without fungal genome pre-treatment (condition A) and PCR reaction using reagent $C$ with fungal genome pretreatment (condition B). Most of DNA bands which were previously not amplified using condition A were amplified using condition B (Figure $5 \mathrm{a}$ and $\mathrm{b}$, respectively). Discrepancies were described as follow. Mixed culture from Fusarium-wilt infected banana plant was showed a fade DNA band for FocTR4. It was ambiguous since molecular marker for fungi (ITS) and for Fusarium (TEF-1 $\alpha$ ) were not present. In contrast, all Foc TR4 markers were confirmed as positive under condition B for mixed culture from Fusarium-wilt infected banana plant. It was previously considered that crude tissue of Fusarium-wilt infected banana plant do not contain any Fusarium species, since

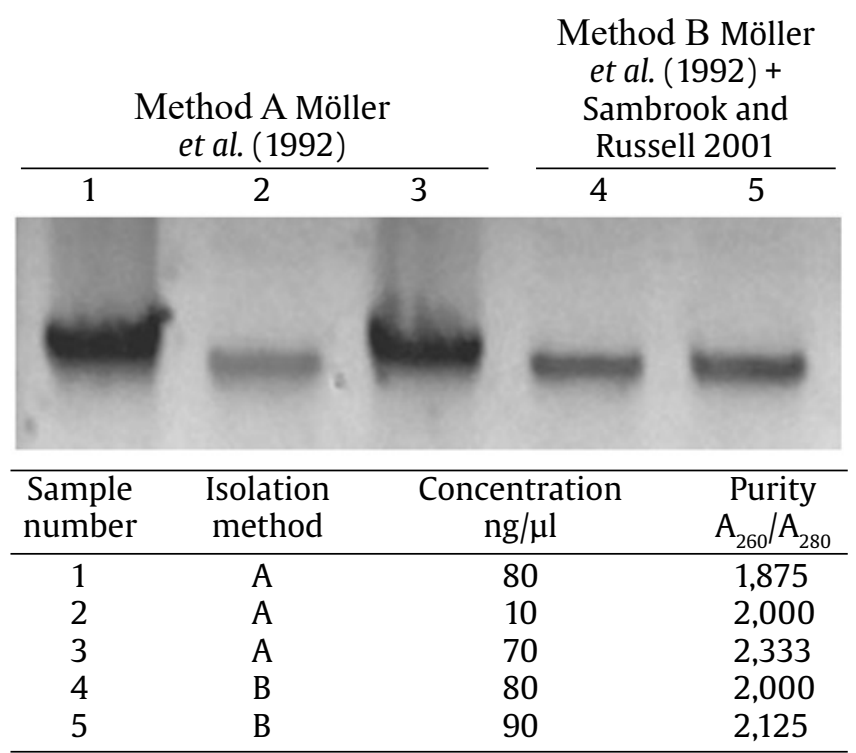

$\overline{\text { Figure 3. Comparison of fungal genome isolate obtained }}$ from different isolation method, Method A with a slight modification and Method A combined with DNA precipitation method using ammonium acetate as described in Method B. Electropherogram of isolated fungal genome and a table of DNA genome concentration and purity were provided

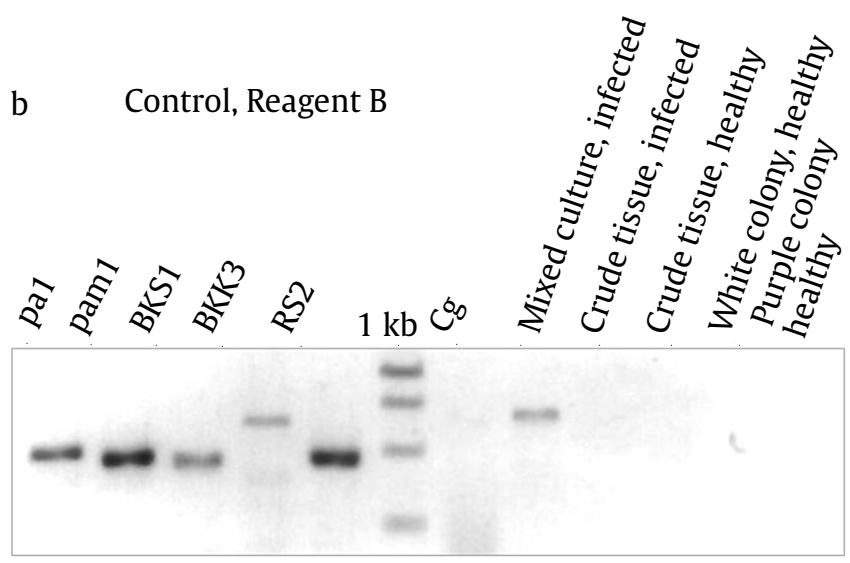

a

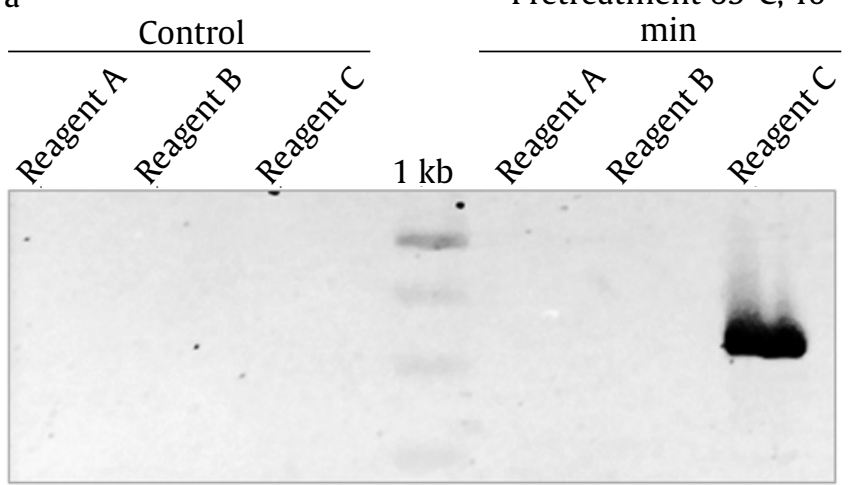

Pretreatment $65^{\circ} \mathrm{C}, 10$ (n)

Figure 4. Visualization of amplified DNA fragment on agarose gel (a) PCR mix reagent C with pre-treatment of genome DNA sample (heating at $65^{\circ} \mathrm{C}$ for 10 minutes before mixed into PCR reagents) enable the amplification of an ITS DNA fragment from Foc TR4 pure culture used in this experiment. (b) Five out of eleven samples which amplified using PCR mix reagent B showed no ITS DNA fragment. No pre-treatment were performed for these samples prior to PCR amplification. DNA marker (1 kb ladder) showing bands of 250, 500, 750, and 1,000 bp 
a

Infected

Mixed culture Crude tissue ITS EF Foc4 ITS EF Foc4 $1 \mathrm{~kb}$

Crude tissue Purple colony White colony ITS EF Foc4 ITS EF Foc4 ITS EF Foc4

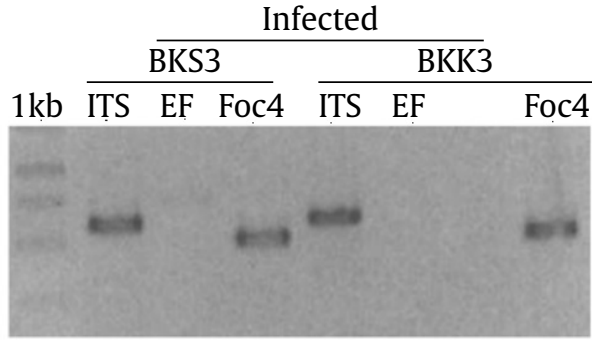

b

Pretreatment $65^{\circ} \mathrm{C}, 10 \mathrm{~min}$, reagent $\mathrm{C}$

\begin{tabular}{|c|c|c|}
\hline & ed & Healthy \\
\hline $\begin{array}{l}\text { Mixed } \\
\text { culture }\end{array}$ & Crude & $\begin{array}{l}\text { Crude } \\
\text { tissue }\end{array}$ \\
\hline
\end{tabular}

\begin{tabular}{|c|c|c|}
\hline Healthy & Infected & Healthy \\
\hline & Crude & \\
\hline
\end{tabular}

\begin{tabular}{cc}
$\frac{\text { Infected }}{\text { BKS3 }}$ & Bealthy \\
& BK3 \\
\hline
\end{tabular}

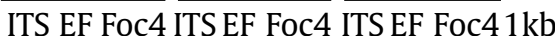
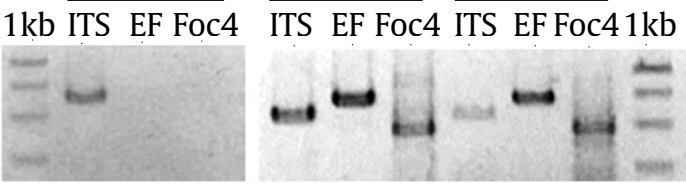

$1 \mathrm{~kb}$ ITS EF Foc4 ITS EF Foc4
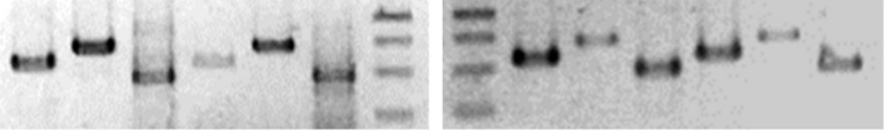

Figure 5. Inconsistence results during Foc TR4 molecular detection using different PCR methods. (a) Amplification of ITS, TEF-1 $\alpha$ F, and FocTR4 DNA fragments using PCR mix reagent B without pre-treatment. (b) Amplification of ITS, TEF-1 $\alpha$, and FocTR4 DNA fragments using PCR mix reagent $C$ with pre-treatment of genome DNA sample (heating at $65^{\circ} \mathrm{C}$ for 10 minutes before mixed into PCR reagent). DNA marker ( $1 \mathrm{~kb}$ ladder) showing bands of 250 , 500,750 , and 1,000 bp. ${ }^{*}$ Re-PCR was performed

Table 2. BLAST analysis of PCR amplicons from Foc TR4 isolate and banana samples

\begin{tabular}{|c|c|c|c|c|c|}
\hline Sample & $\begin{array}{l}\text { Primer } \\
\text { pairs }\end{array}$ & $\begin{array}{l}\text { Amplicon size } \\
\text { (bp) }\end{array}$ & $\begin{array}{l}\text { The closest organism in GenBank } \\
\text { (accession number) }\end{array}$ & Similarity (\%) & E-value \\
\hline \multirow[t]{3}{*}{ Foc TR4 } & ITS5/4 & 483 & $\begin{array}{l}\text { Fusarium oxysporum f. cubense strain FOC4 } \\
\text { internal transcribed spacer 1, partial } \\
\text { sequence; } 5.8 \mathrm{~S} \text { ribosomal RNA gene and } \\
\text { internal transcribed spacer } 2 \text {, complete } \\
\text { sequence (KC869373.1) }\end{array}$ & 100 & 0.00 \\
\hline & EF-1/2 & 657 & $\begin{array}{l}\text { Fusarium oxysporum isolate F0304 translation } \\
\text { elongation factor } 1 \text { alpha (EF1a) gene, } \\
\text { partial cds (JQ965436.1) }\end{array}$ & 99 & 0.00 \\
\hline & FocTR4-F/R & 428 & $\begin{array}{l}\text { Fusarium oxysporum f. cubense strain FOC4 } \\
28 \mathrm{~S} \text { ribosomal RNA gene and } 28 \mathrm{~S}-18 \mathrm{~S} \\
\text { ribosomal RNA intergenic spacer, partial } \\
\text { sequence (KC869392.1) }\end{array}$ & 100 & 0.00 \\
\hline $\begin{array}{l}\text { Crude tissue } \\
\text { of Fusarium } \\
\text { wilt-nfected } \\
\text { banana plant }\end{array}$ & FocTR4-F/R & 378 & $\begin{array}{l}\text { Fusarium oxysporum f. cubense strain VCG } \\
01213 \text { 28S-18S ribosomal RNA intergenic } \\
\text { spacer, partial sequence (MG211816.1) }\end{array}$ & 99 & 0.00 \\
\hline \multirow[t]{3}{*}{$\begin{array}{l}\text { Purple colony } \\
\text { grown from } \\
\text { healthy } \\
\text { banana plant }\end{array}$} & ITS4 & 490 & $\begin{array}{l}\text { Fusarium proliferatum isolate DSM } 106835 \\
\text { small subunit ribosomal RNA gene, partial } \\
\text { sequence; internal transcribed spacer 1, } \\
5.8 \text { S ribosomal RNA gene, and internal } \\
\text { transcribed spacer 2, complete sequence; } \\
\text { and large subunit ribosomal RNA gene, } \\
\text { partial sequence (MH055399.1) }\end{array}$ & 100 & 0.00 \\
\hline & EF-1 & 639 & $\begin{array}{l}\text { Fusarium proliferatum isolate } \\
\text { translation elongation factor } \\
\text { (tef1a) gene, partial cds }\end{array}$ & 99 & 0.00 \\
\hline & FocTR4-F & 419 & $\begin{array}{l}\text { Fusarium oxysporum f. cubense strain VCG } \\
01213 \text { 28S-18S ribosomal RNA intergenic } \\
\text { spacer, partial sequence (MG211816.1) }\end{array}$ & 100 & 0.00 \\
\hline
\end{tabular}


negative result for TEF-1 $\alpha$ and FocTR4 markers. However, under PCR condition B crude tissue of Fusarium-wilt infected plant showed positive result for all Foc TR4 markers. Fungal DNA was not detected in crude sample of healthy banana plant tissue, confirmed by both methods. White and purple colony which previously showed no Foc TR4 marker under PCR condition A, showed that only purple colony positive for Foc TR4 markers under PCR condition B. Sample BKK3 and BKS3 which previously showed ambiguous results (ITS and FocTR4 detected but no TEF-1 $\alpha$ DNA fragment), subsequently confirmed positive for all Foc TR4 markers.

Single sharp bands of ITS, TEF- $1 \alpha$, and FocTR4 DNA fragments showed expected sizes: 550, 648, and $\sim 463$ bp for amplification using ITS5/4, EF-1/2 and FocTR4-F/R primer pairs, respectively (Figure 5b). BLAST analysis of sequenced fragments showed similarity with desired genes with high similarity $(\geq$ 99\% similarity and E-value $=0$, Table 2 ). ITS, TEF- $1 \alpha$, and FocTR4 DNA sequences of Foc TR4 pure culture used in this experiment are available at GenBank with accession numbers MG211816, MG203899, and MG211817, respectively. FocTR4 DNA sequence from Fusarium wilt-infected banana tissue sample and ITS, TEF-1 $\alpha$, and FocTR4 DNA sequences from the healthy banana tissue sample are available at GenBank with accession numbers MH535859, MH517446, MH535857, and MH535858, respectively.

\section{Discussion}

Molecular detection of Foc TR4 was associated with fungal genome isolation and amplification of Foc TR4 specific primers. A fast and robust method was needed to ensure the reliability of Foc TR4 molecular detection. We demonstrate that substituting sodium acetate with ammonium acetate in DNA precipitation step described in Möller et al. (1992) method was able to reduce the fungal genome isolation time by an approximately 30 minutes without affecting the result and downstream process. A brief method enables the faster detection of Foc TR4 which will be advantageous for the stakeholders to consider and decide the strategy of Fusarium wilt management. We found that some fungal samples ware troublesome to be amplified using ITS5/4, EF-1/2, and FocTR4-F/R primer pairs and need a pre-treatment before mixed into PCR reagents. Adding a pre-treatment step (incubation of genome samples in $65^{\circ} \mathrm{C}, 10$ minutes) greatly enhance the performance of
PCR reaction and a lower chance of getting false negative detection result. We suggested a pre-treatment step before amplification of any fungal genomes for more reliable and consistent result. Veal et al. (2012) suggest that denaturing the input DNAs and snap cooling on ice prior to PCR reaction were considered as the most effective method to improve amplification efficiencies in Illumina Infinium genotyping. It was considered that heating the DNA in $65^{\circ} \mathrm{C}$ for 10 minutes was high enough to denature the double-stranded structure enabling primer invasion to facilitate amplification (Wilhelm et al. 1974). This temperature might also inactivate any inhibiting compound carried away from the previous step. However, further study should be performed since not all fungal sample needed this pretreatment (Figure 4b). It was stated that the efficiency of DNA amplification could be varied across the genome and between the samples (Veal et al. 2012).

Foc TR4 pure isolate used in this experiment was confirmed molecularly as Fusarium oxysporum f. sp. cubense tropical race 4. Visual symptoms of Fusarium wilt-infected banana plant, including yellowing and necrotic leaves and vascular discoloration were confirmed by molecular detection. Foc TR4 which is the most pathogenic Foc race was detected in Fusarium wilt-infected banana plant, confirmed by positive Foc TR4 markers either for mixed culture or crude tissue of Fusarium wilt-infected banana plant (Figure 5b). Purple colony which was previously predicted as Foc TR4 was considered as a $F$. proliferatum culture with Foc TR4 contamination. ITS and TEF- $1 \alpha$ of purple colony showed a high similarity to $F$. proliferatum but also positive result for FocTR4 DNA fragment which showed high similarity with Foc TR4 intergenic spacer in GenBank (Figure 5b, Table 2). It was demonstrated that although no fungal DNA was detected using PCR method, a further enrichment of fungal culture in PDA medium showed that there were a trace amount of Foc TR4 contamination in healthy banana plant tissue. Still, a trace amount of Foc TR4 should not be ignored since it has the risk of causing Fusarium wilt outbreak in the future, especially when the plant immune is decreased and the environment is favorable.

In conclusion, this study demonstrated a faster fungal DNA isolation by combining Möller et al. (1992) method with ammonium acetate DNA precipitation as described in Sambrook and Russell (2001) without affecting the result and downstream process. The most important remark in this study is that the pretreatment of genome samples prior to PCR of Foc TR4 
molecular markers and the right choice of robust PCR reagent could overcome the low efficiency of DNA amplification of stubborn samples. These strategies enables a reliable andconsistent results of molecular detection of Foc TR4 as well as minimizing the risk of getting false negative results.

\section{Acknowledgments}

This work was supported by Research and Innovation Project for Research Groups in Bandung Institute of Technology (Grant number: SITH.PN-6-012015). We would like to thank Indonesian Tropical Fruit Research Institute for providing Foc TR4 (VCG 01213) pure culture. We also thank ITB Banana Research Group for providing additional fungal genome samples of Fusarium wilt-infected banana plants from various place in Bali.

\section{References}

Altschul S. 1997. Gapped BLAST and PSI-BLAST: a new generation of protein database search programs. Nucleic Acids Res 25:3389-3402.

Dita MA et al. 2010. A molecular diagnostic for tropical race 4 of the banana Fusarium wilt pathogen. Plant Pathol 59:348-357.

FAOSTAT 2018. Top 10 Country Production of Bananas. Available at: http://www.fao.org/faostat/en/\#rankings/countries_ by_commodity [Date accessed: 23 August 2018]

Katan T. 1999. Current status of vegetative compatibility groups in Fusarium oxysporum. Phytoparasitica 27:51-64.

Li B et al. 2012. Development of a loop-mediated isothermal amplification assay for rapid and sensitive detection of Fusarium oxysporum f. sp. cubense race 4. Eur J Plant Pathol 135:903-911.
Lin Y-H et al. 2009. Development of a molecular marker for specific detection of Fusarium oxysporum $\mathrm{f}$. sp. cubense race 4. Eur J Plant Pathol 123:353-365.

Möller EM et al. 1992. A simple and efficient protocol for isolation of high molecular weight DNA from filamentous fungi, fruit bodies, and infected plant tissues. Nucleic Acids Res 20:6115-6116.

O'Donnell Ket al. 1998. Multiple evolutionary origins of the fungus causing Panama disease of banana: concordant evidence from nuclear and mitochondrial gene genealogies. Proc Natl Acad Sci 95:2044-2049.

Ploetz RC, Evans EA. 2015. The future of global banana production. In: Janick J (Eds.). Horticultural Reviews: Volume 43. New Jersey: John Wiley and Sons Inc. pp. 311-352.

Sambrook J, Russell DW. 2001. Molecular Cloning: A Laboratory Manual. 3rd ed. New York: CSHL Press.

Singha IM et al. 2016. Identification and characterization of Fusarium sp. using ITS and RAPD causing fusarium wilt of tomato isolated from Assam, North East India. J Genet Eng Biotechnol 14:99-105.

Stucky BJ. 2012. SeqTrace: a graphical tool for rapidly processing DNA sequencing chromatograms. J Biomol Tech 23:90-93.

Veal CD et al. 2012. A mechanistic basis for amplification differences between samples and between genome regions. BMC Genomics 13:455. DOI:10.1186/14712164-13-455

White T et al. 1990. Amplification and direct sequencing of fungal ribosomal RNA genes for phylogenetics. In: Innis M, Gelfand D, JS, TW (Eds.). PCR Protocols: A Guide to Methods and Applications. Orlando: Academic Press. pp. 315-322.

Wilhelm FX et al. 1974. Conformational changes of histones and DNA during the thermal denaturation of nucleoprotein. Eur J Biochem 45:431-443. 